\title{
PELATIHAN APLIKASI OPEN BROADCAST STUDIO BAGI GURU SMK NEGERI 2 PINGGIR
}

\author{
Rizki Novendra ${ }^{1}$, Afriansyah ${ }^{2}$, Eddis Syahputra Pane ${ }^{3}$ \\ ${ }^{1}$ Fakultas Ilmu Komputer Universitas Lancang Kuning, Pekanbaru, Indonesia \\ 2,3 Fakultas IImu Komputer Universitas Lancang Kuning, Pekanbaru, Indonesia \\ email (rizkinovendra@unilak.ac.id ${ }^{1}$, afriansyah@unilak.ac.id ${ }^{2}$, jugulspane@gmail.com ${ }^{3}$ )
}

\begin{abstract}
Abstrak: Dunia Pendidikan dituntut untuk dapat melakukan adaptasi dengan keadaan. Proses penyesuaian atau adaptasi ini dapat terlaksana dengan bantuan teknologi informasi. Salah satu aplikasi yang dapat membantu dalam proses adaptasi pembelajaran, rapat dan seminar yaitu Zoom Cloud Meeting dan Obs Studio. Mitra dalam kegiatan ini adalah Guru SMK Negeri 2 Pinggir. Kegiatan pengabdian ini memiliki beberapa tahapan yaitu pemaparan materi terkait aplikasi yang digunakan, tahap pendampingan praktek mengoprasikan perangkat pendukung yang digunakan untuk broadcast dan yang terakhir yaitu tahap evauasi. Hasil dari evaluasi pengabdian diperoleh dengan cara menyebarkan kuesioner kepada para guru. Dari 12 pertanyaan atau kuesioner tentang kepuasan terhadap pelaksanaan kegiatan pengabdian kepada masyarakat, maka diperoleh rata-rata rentang 4 dari 5 rentang yaitu dengan tingkat kepuasan puas
\end{abstract}

Kata Kunci: Pelatihan, Broadcasting, OBS

Abstract: The world of education is required to be able to adapt to the circumstances. This adjustment or adaptation process can be carried out with the help of information technology. One application that can assist in the adaptation process of learning, meetings and seminars is Zoom Cloud Meeting and Obs Studio. Partners in this activity are teachers of SMK Negeri 2 Pinggir. This service activity has several stages, namely the presentation of material related to the application used, the stage of practical assistance in operating the supporting devices used for broadcast and the last stage is the evaluation stage. The results of the service evaluation were obtained by distributing questionnaires to the teachers. Of the 12 questions or questionnaires about satisfaction with the implementation of community service activities, the average range obtained is 4 out of 5 ranges, namely the level of satisfaction is satisfied

Keywords: training, Broadcasting, $O B S$

\section{Pendahuluan}

Perkembangan teknologi saat ini berkembang sangat pesat, tak terkecuali pada bidang Pendidikan. Indonesia saat ini sedang dilanda wabah pandemic Covid-19. Yang mana wabah ini memaksa proses pembelajaran secara tatap muka atau luring ditiadakan. Para siswa dan mahasiswa dipaksa untuk tetap dirumah sebagai upaya pencegahan penyebaran atau penularan Covid-19 (Purwanto et al., 2020)

Penyesuaian atau proses adaptasi menjadi salah satu kunci untuk bertahan dimasa pandemi. Kegiatan-kegiatan yang sebelumnya bersifat luring dan mengumpulkan banyak orang harus dialihkan secara online. Contoh kegiatan yang biasanya mengumpulkan 
banyak orang seperti proses belajar mengajar, seminar (nasional/internasional), dan rapat untuk para pimpinan tinggi. Disinilah peran kemajuan teknologi diperlukan untuk proses penyesuaian atau adaptasi.

Kemajuan yang terjadi dalam dunia teknologi informasi dan visualisasi komunikasi memunculkan peluang maupun tantangan baru dalam dunia pendidikan. Peluang baru yang muncul termasuk akses yang lebih luas terhadap konten multimedia yang lebih kaya, dan berkembangnya metode pembelajaran baru yang tidak lagi dibatasi oleh ruang dan waktu. Di sisi lain kemajuan teknologi dengan beragam inovasi digital yang terus berkembang juga menghadirkan tantangan baru bagi penyelenggara pendidikan untuk terus menyesuaikan infrastruktur pendidikan dengan teknologi baru tersebut

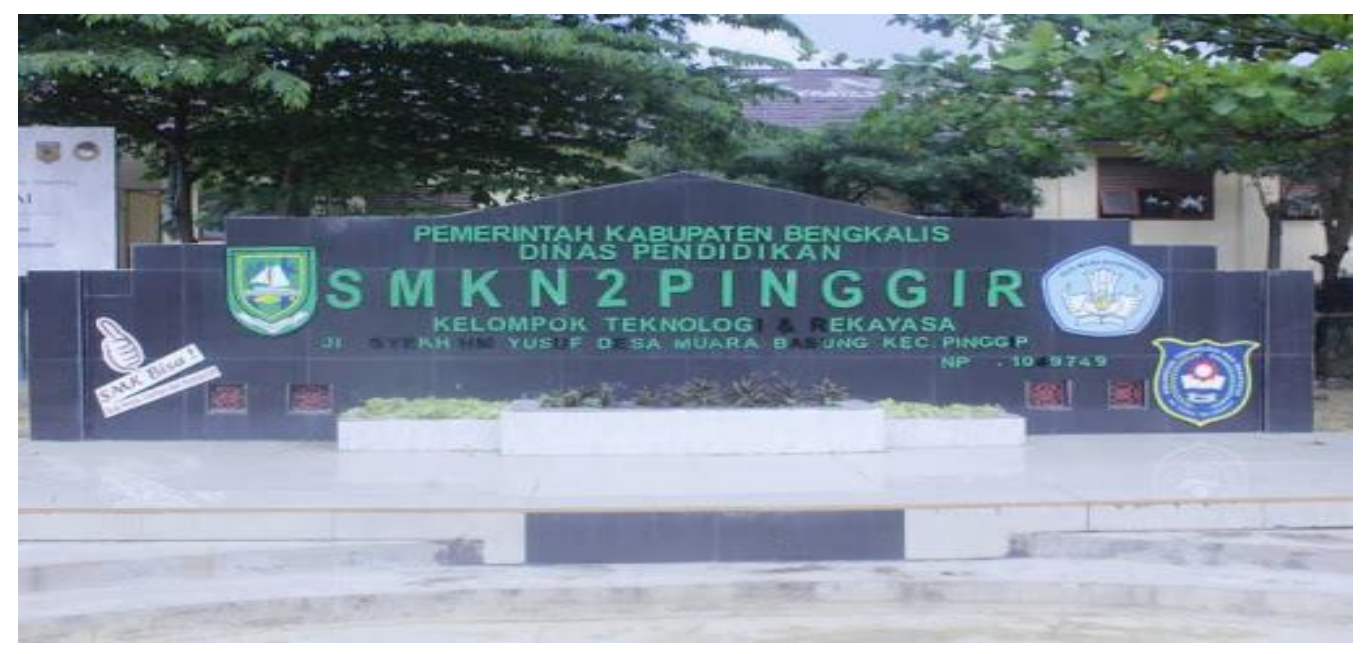

Gambar. 1. SMK Negeri 2 Pinggir

Sebagian besar dari proses penyesuaian atau adaptasi telah dilaksanakan di Guru SMK Negeri 2 Pinggir. Proses atau kegiatan tersebut meliputi kegiatan belajar-mengajar, dan rapat penting antar Guru. Namun tuntutan akan penyesuaian atau adaptasi tidak hanya sampai disitu saja. Terdapat kegiatan yang membutuhkan kondisi yang memerlukan perlatan serta hard skill yang memadai. Kegiatan tersebut merupakan Live Broadcasting. SMK Negeri 2 Pinggir sebagai salah satu SMK Negeri, hendaknya dapat memfasilitasi dan menjalankan proses adaptasi tersebut. Oleh karena itulah perlu dilakukannya peningkatan pengetahuan dalam proses sosialisasi atau pelatihan Guru SMK Negeri 2 Pinggir tentang bagaimana cara untuk dapat melakukan kegiatan live broadcasting 


\section{Metode}

Metode pelaksanaan pengabdian ini adalah dengan melakukan pelatihan oleh tim pengabdian kepada Guru SMK Negeri 2 Pinggir. Adapun tahapannya adalah sebagai berikut.

1. Tahap pertama yaitu fase pemaparan materi dasar tentang zoom dan obs. Materi tersebut meliputi :

a. $\quad$ Proses download dan install aplikasi zoom dan obs

b. $\quad$ Proses membuat rapat baru pada zoom

c. Proses pengenalan vitur yang terdapat pada aplikasi obs

d. Proses kolaborasi antara aplikasi zoom dan obs

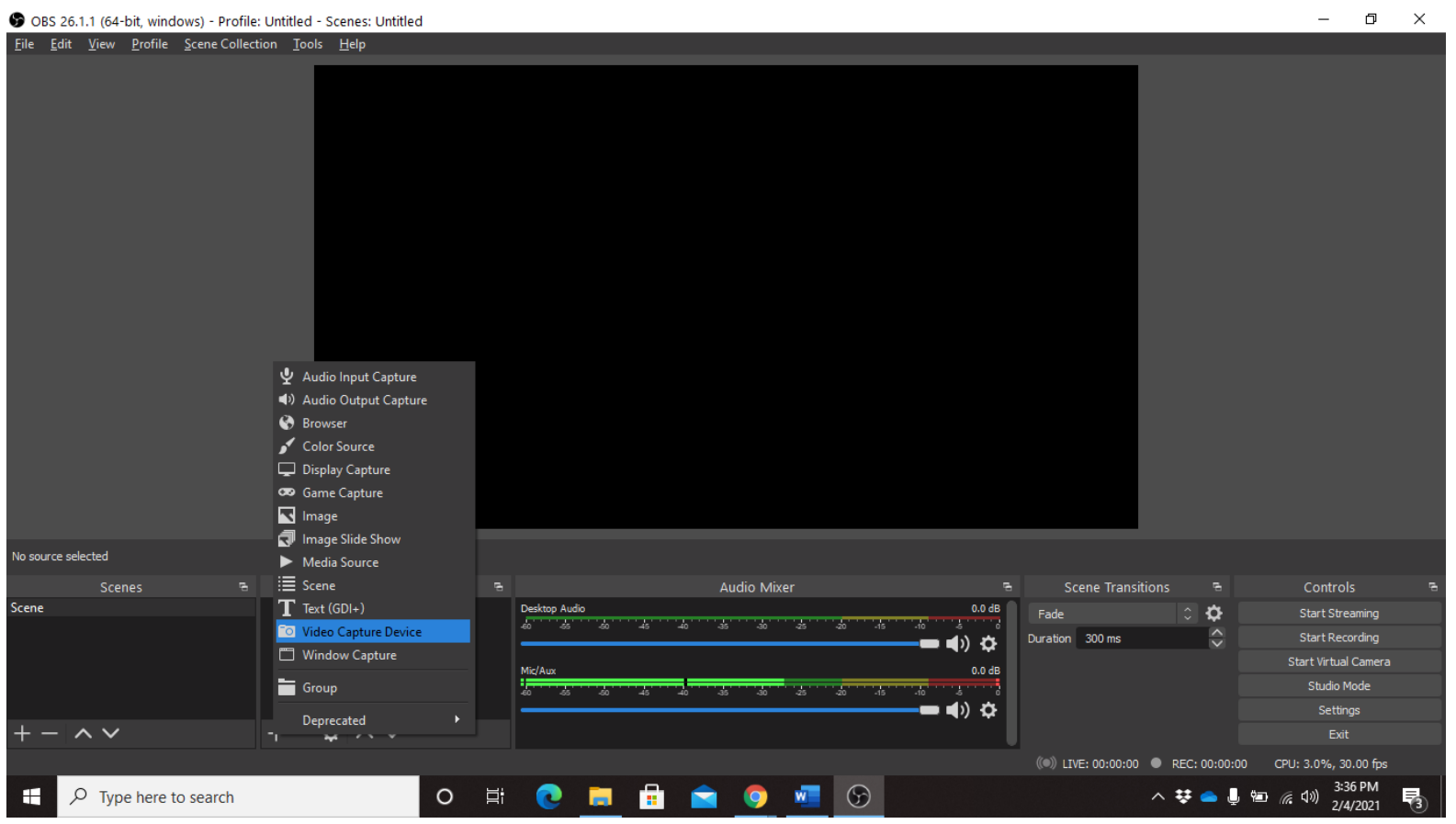

Gambar 2. Tampilan aplikasi OBS

2. Tahap kedua yaitu fase pendampingan praktek mengoperasikan perangkat pendukung yang digunakan untuk kegiatan broadcasting.

Materi tersebut meliputi :

- $\quad$ Proses setup kamera

- $\quad$ Proses setup audio

- $\quad$ Menghubungkan kamera dengan aplikasi obs

- $\quad$ Proses setup video capture device, add image, add teks dan display capture

- $\quad$ Proses control enable dan disable sources item

- $\quad$ Proses start virtual camera

- $\quad$ Proses memilih audio device dan obs virtual camera pada aplikasi zoom 
3. Tahapan ketiga yaitu evaluasi, pada fase ini tim pengabdian akan memberikan kuesioner kepada peserta untuk melihat hasil dari kegiatan ini. Hasil atau score tersebut akan dikonversi dalam bentuk tabel guna untuk mempermudah menganalisis data tentang peningkatan kemampuan peserta dalam menggunakan aplikasi zoom dan obs.

\section{Hasil dan Pembahasan}

Pengabdian dilakukan dengan tiga tahapan kepada Guru SMK Negeri 2 Pinggir. Pelaksanaan kegiatan dirancang dalam bentuk daring/online menggunakan platform aplikasi zoom. Peserta pelatihan yakni Guru SMK Negeri 2 Pinggir yang berjumlah 5 orang. Adapun tahapannya adalah sebagai berikut. Adapun kegiatan pengabdian ini dilaksanakan pada: Hari Tanggal : Kamis/ 01 Juli 2021 Pukul : 09.00 WIB s.d 11.00 WIB Aplikasi

https://us02web.zoom.us/j/5568515767?pwd=ejZ1TEJNbzNIK253WmZ6dkJTWW15Zz09

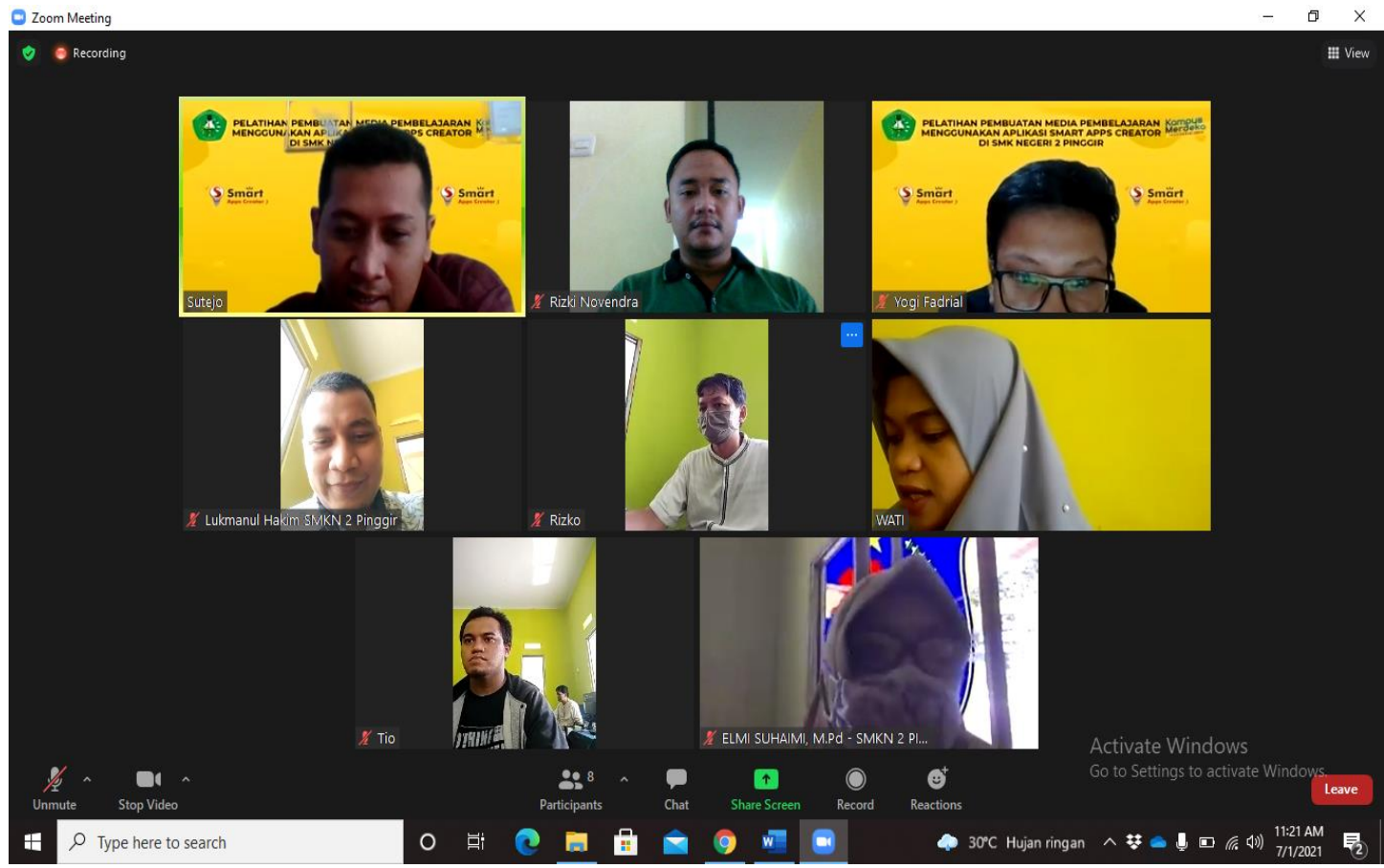

Gambar 3. Peserta pelatihan OBS

1. Tahap pertama pemaparan materi

Pada tahapan ini, tim melakukan pemaparan materi terkait aplikasi zoom dan obs. Pada aplikasi zoom, peserta diberikan materi terkait cara penggunaan zoom yaitu penjelasan pada fitur new meeting dan schedule. Sedangkan pada aplikasi OBS, peserta 
mendapatkan pemaparan tentang fitur Source add video capture, Source add teks, Source add image.

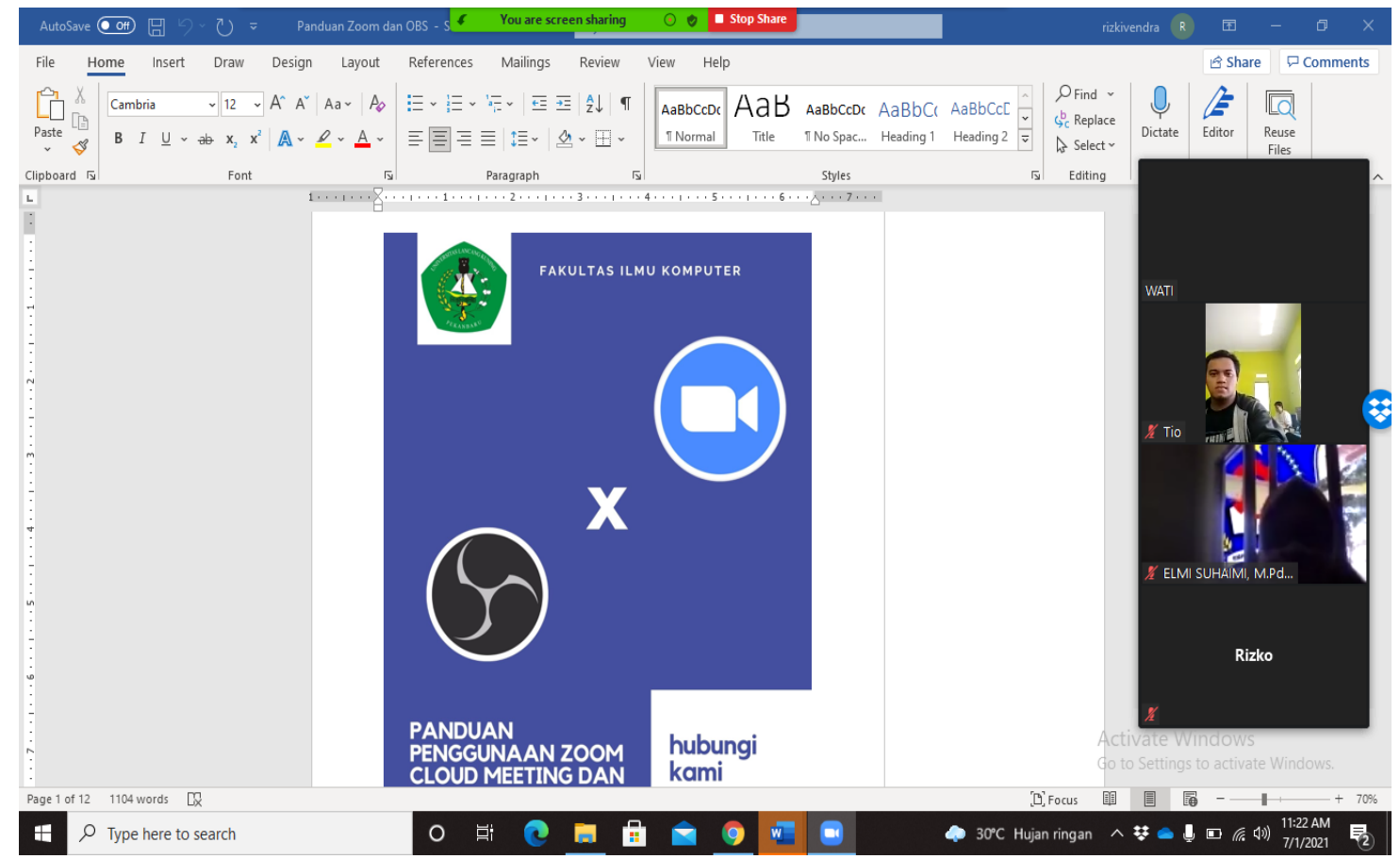

Gambar 4. Pemaparan materi obs dan zoom

2. Tahap ke dua demo aplikasi obs dan setup

Setelah memaparkan materi terkait dua aplikasi terebut. Pada tahapan ini tim pengabdian kepada masyarakat mendemokan cara menghubungkan obs dan zoom serta kamera dslr. Satu persatu tools pendukung dijeaskan fungsi dan kegunaannya, serta proses dan arah plug in alat didemokan. Terakhir tahapan paling penting yaitu menjadikan obs sebagai virtual kamera yang akan digunakan pada aplikasi zoom.

3. Tahap ke tiga evaluasi

Tahapan ketiga yaitu evaluasi, pada fase ini tim pengabdian memberikan kuesioner kepada peserta untuk melihat hasil dari kegiatan ini. Hasil atau score tersebut akan dikonversi dalam bentuk diagram guna untuk mempermudah menganalisis data tentang peningkatan kemampuan peserta dalam menggunakan aplikasi obs dan zoom. Pada pengabdian ini tim IbM melakukan pengukuran tingkat kepuasan peserta pelatihan khususnya kepada Guru SMK Negeri 2 Pinggir dengan menggunakan kuisioner, hasil dari kuisioner tersebut menunjukkan bahwa : 


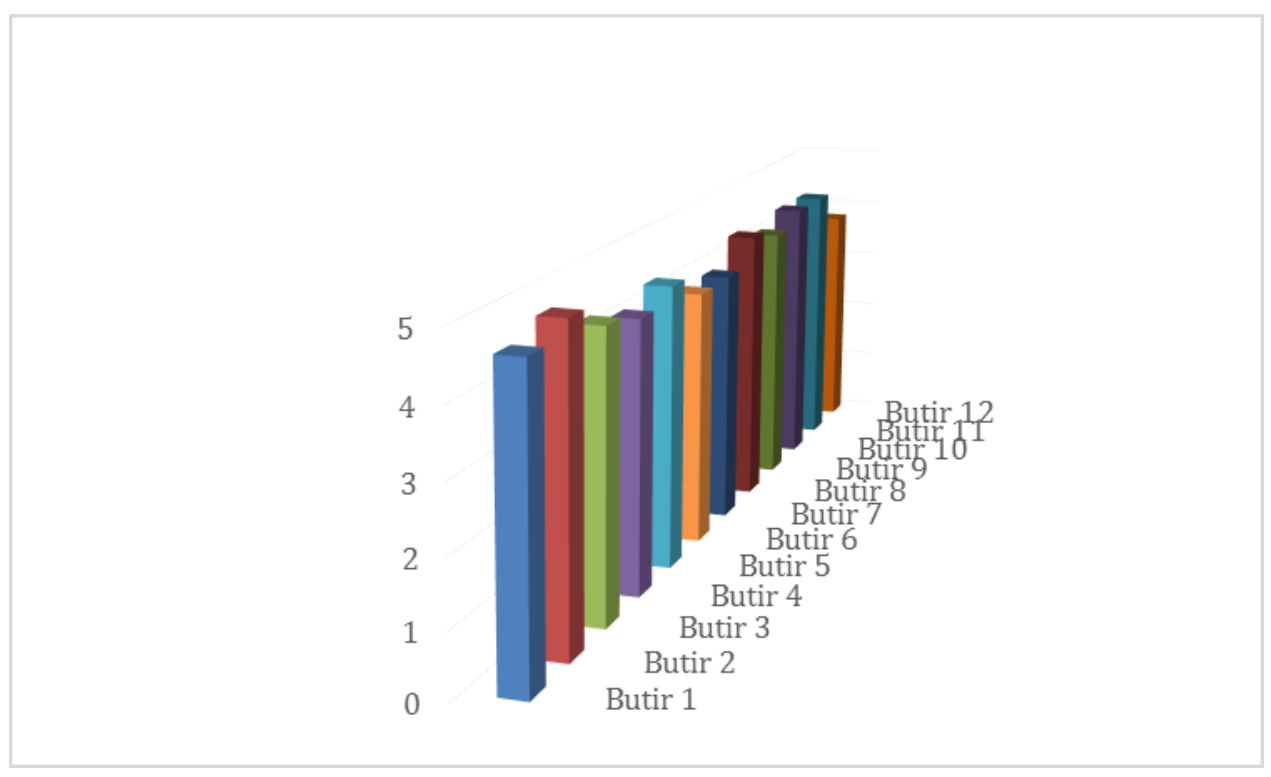

Gambar 5. Tingkat kepuasan perbutir kuesioner

Kuesioner disebarkan kepada peserta, yakni guru SMK Negeri 2 Pinggir berjumlah 5 orang. Dari 12 pertanyaan atau kuesioner tentang kepuasan terhadap pelaksanaan kegiatan pengabdian kepada masyarakat, maka diperoleh rata-rata rentang 4 dari 5 rentang yaitu dengan tingkat kepuasan puas. Berikut daftar pertanyaan kuesioner :

Tabel 5.1 Daftar Kuesioner

\begin{tabular}{|c|l|c|}
\hline No & \multicolumn{1}{|c|}{ Pertanyaan } & Nilai rata-rata \\
\hline 1 & Materi PkM sesuai dengan kebutuhan Mitra/Peserta & 4,6 \\
\hline 2 & Kegiatan PkM yang dilaksanakan sesuai harapan Mitra & 4,8 \\
\hline 3 & Cara pemateri menyajikan materi PkM menarik & 4,4 \\
\hline 4 & Materi yang disajikan jelas dan mudah dipahami & 4,2 \\
\hline 5 & $\begin{array}{l}\text { Waktu yang disediakan sesuai untuk penyampaian materidan } \\
\text { kegiatan PkM }\end{array}$ & 4,6 \\
\hline 6 & $\begin{array}{l}\text { Mitra berminat untuk mengikuti kegiatan PkM selamasesuai } \\
\text { kebutuhan Mitra/peserta }\end{array}$ & 4,4 \\
\hline 7 & $\begin{array}{l}\text { Anggota PkM yang terlibat dalam kegiatan pengabdianmasyarakat } \\
\text { memberikan pelayanan sesuai dengankebutuhan }\end{array}$ & \\
\hline 8 & Kegiatan PkM dilakukan secara berkelanjutan & 4 \\
\hline & $\begin{array}{l}\text { Setiap keluhan/pertanyaan/permasalahan yang } \\
\text { diajukanditindaklanjuti dengan baik oleh narasumber/anggota } \\
\text { pengabdian yang terlibat }\end{array}$ & 4 \\
\hline 10 & $\begin{array}{l}\text { Mitra mendapatkan manfaat langsung dari kegiatan PkMyang } \\
\text { dilaksanakan }\end{array}$ & 4,4 \\
\hline
\end{tabular}




\begin{tabular}{|c|l|c|}
11 & Kegiatan PkM berhasil meningkatkankesejahteraan/kecerdasan mitra & 4,4 \\
\hline 12 & $\begin{array}{l}\text { Secara Umum, mitra puas terhadap kegiatan PkMSurvey Kepuasan } \\
\text { Kegiatan PkM(Mitra/Peserta) }\end{array}$ & 3,8 \\
\hline
\end{tabular}

\section{Kesimpulan}

Berdasarkan penjelasan dari kuisioner dapat diambil kesimpulan bahwa pelatihan aplikasi obs dapat membantu Guru SMK Negeri 2 Pinggir dalam melaksanakan rapat secara virtual dengan menggunakan kamera DSLR yang terhubung dengan aplikasi obs dan zoom. Dengan adanya aplikasi ini sekolah dapat melakukan rapat maupun seminar secara online sendiri.

\section{Ucapan Terima Kasih}

Bismillahhirahmanirrahim, Puji dan syukur kami panjatkan kepada Allah SWT atas berkat, rahmat, hidayah, dan karunia-Nya sehingga peneliti dapat menyelesaikan jurnal pengabdian ini dengan lancar. Kemudian, shalawat serta salam-Nya, mudah-mudahan terlimpah curah ke pangkuan baginda Rasulullah SAW, beserta keluarganya, sahabatnya, dan umatnya yang masih turut dengan ajarannya. Amin. Berkat rahmat dan karunia-Nya, peneliti dapat menyelesaikan pengabdian kepada masyarakat yang berjudul "Pelatihan Aplikasi OBS Bagi Guru SMK Negeri 2 Pinggir". Jurnal ini tidak akan selesai tanpa dukungan serta bantuan dari berbagi pihak terkait, dan dengan segala kerendahan hati peneliti mengucapkan terima kasih yang sebesar-besarnya.

\section{Daftar Pustaka}

Monica, J., \& Fitriawati, D. (2020). Efektivitas Penggunaan Aplikasi Zoom Sebagai Media Pembelajaran Online Pada Mahasiswa Saat Pandemi Covid-19. Jurnal Communio: Jurnal Jurusan IImu Komunikasi, 9(2), 1630-1640. https://doi.org/10.35508/jikom.v9i2.2416

Purwanto, A., Pramono, R., Asbari, M., Santoso, P. B., Wijayanti, L. M., Choi, C. H., \& Putri, R. S. (2020). Studi Eksploratif Dampak Pandemi COVID-19 Terhadap Proses Pembelajaran Online di Sekolah Dasar. EduPsyCouns: Journal of Education, Psychology and Counseling, 2(1), 1-12. https://ummaspul.ejournal.id/Edupsycouns/article/view/397

Putri, R., Budiarti, N., Sukaridhoto, S., Fandi, M., Nahdlatul, U., Surabaya, U., Elektronika, P., \& Surabaya, N. (2020). COST EFFECTIVE OF ONLINE GRADUATION CEREMONY AT SDIT AL-USWAH SURABAYA. 1, 20-29.

Anggraini, P., \& Sularno, S. (2021). OPTIMASI PENGGUNAAN STREAM LABS UNTUK PENUNJANG PEMBUATAN MATERI DARING DOSEN PRODI SISTEM INFORMASI UNIDHA. Jurnal Teknologi Dan Sistem Informasi Bisnis, 3(1), 185-191.

Budiarti, R. P. N., Sukaridhoto, S., \& Fandi, M. (2020). Cost Effective of Online Graduation Ceremony at SDIT AL-USWAH Surabaya. Prosiding SEMADIF, 1. 
Hardianto, R., \& Wiza, F. (2021). SOSIALISASI MEMBUAT VIDEO PEMBELAJARAN SEBAGAI PENUNJANG PEMBELAJARAN DIMASA PANDEMI COVID-19. J-COSCIS: Journal of Computer Science Community Service, 1(1), 37-41.

Qorib, A., \& Zaniyati, H. S. (2021). Penggunaan Open Broadcast Software Studio dalam Mendesain Video Pembelajaran Era Pandemi. Syaikhuna: Jurnal Pendidikan Dan Pranata Islam, 12(1), 87-98.

Maryani, K. (2020). Penilaian dan Pelaporan Perkembangan Anak Saat Pembelajaran di Rumah di Masa Pendemi Covid-19. Murhum: Jurnal Pendidikan Anak Usia Dini, 4152.

Ma'ruufah, M. A., Gestiardi, R., \& Chumdari, M. (2021). PEMANFAATAN TEKNOLOGI DALAM PEMBELAJARAN DARING ERA COVID-19 PADA PESERTA DIDIK KELAS $V$ SEKOLAH DASAR. JURNAL NALAR PENDIDIKAN, $9(1), 36-42$. 